\title{
Küçük ve Orta Ölçekli Şirketlerde Finansal Performans ve Kurumsal Yönetim İlişkisi: Borsa İstanbul Gelişen Şirketler Piyasası Üzerine Bir Uygulama* Mehmet SAĞLAM ${ }^{1}$, Mehmet Baha KARAN ${ }^{2}$ Özet
}

Bu çalışmanın amacı, Borsa İstanbul'da işlem gören Küçük ve Orta Ölçekli Şirketlerin kurumsal yönetim uygulamalarının, onların finansal performans göstergelerine etkisini ölçmektir. Bu amaçla, 2011-2017 döneminde Borsa İstanbul, Gelişen İşletmeler Pazarı'nda işlem gören 25 şirket incelenmiştir. Bu şirketlerin yönetim kurulu büyüklügü̈, CEO'nun görevde kalma süresi ve ikililiği(duality), yönetim kurulundaki bağımsız yönetici oranı ve kadın yönetici oranı gibi kurumsal yönetim ilkeleri değiş̧kenlerinin şirketlerin ROA (aktif karlılık), ROE (öz sermaye karlılığı) oranlarına test edilmiştir. Araştırmada panel veri regresyon analizi yöntemi kullanılmıștır. Çalışmada panel veri regresyon analizi sonucunda kurumsal yönetim ilkeleri değişkenlerinden sadece CEO'nun görevde kalma süresinin KOBi'lerin finansal performansını olumlu yönde etkilediği ve onlar için önemli bir parametre olduğu sonucuna ulaşılmıştır. Bu sonuç önceki çalışmaları desteklemektedir.

Anahtar kelimeler: Kurumsal Yönetim İlkeleri, Finansal Performans, KOBİ, BİST

Jel Kodu: G3

\section{Relationship between Financial Performance and Corporate Governance in Small and Medium Sized Companies: An Emprical Analysis on Borsa Istanbul Emerging Companies Market}

Abstract

The aim of this study is to measure the impact of corporate governance practices of SMSEs on their own financial performance indicators. For this purpose, 25 companies that are traded in Borsa İstanbul, Emerging Companies Market in 2011-2017 are examined. The major corporate governance principles such as the size of the board of directors of the companies, the duration and duality of the CEO, the ratio of independent directors in the board of directors and the ratio of women managers are used as independent variables. The dependent variables of the model are ROA (asset profitability), ROE (return on equity) of the companies. Panel data regression analysis method was used in the study. As a result of the analysis, it is concluded that only the CEO 's duration in the company in terms of corporate governance principles positively affects the financial performance of SMEs and is an important parameter for them. This result supports previous studies.

Keywords: Corporate Governance Principles, Financial Performance, SME, Istanbul Stock Exchange Jel Codes: G3

\section{Gíriș}

Gelişmiş ülkelerin borsalarında itici güç olarak yer alan Microsoft, Facebook, Amazon ve Apple gibi şirketler, onlarca yll önce finansal piyasalara birer küçük şirket olarak girmiş ve kısa zamanda ürettikleri teknolojiler ile Amerika'nın en önemli şirketleri haline gelmişlerdir. Günümüzde küçük ve orta ölçekli işletmeler ülkelerin ekonomik yapılarının temelini oluşturmaktadır. Yalnız mal ve hizmet üretimi yapmalarının dışında ülke istihdamına verdikleri katkı ile yenilikçi fikir ve ürünlerin oluşturulmasında çok önemli işlevleri vardır. Bu nedenle ülkeler küçük ve orta ölçekli (KOBi) şirketlerin para ve sermaye piyasalarından etkin olarak yararlanmaları için gerekli önlemleri almakta ve finansmanları için bir altyapı olușturmaktadır. Kobilerinin yarattı̆̆ teknolojiyi başarılı bir şekilde kullanan ABD, özellikle NASDAQ borsası ile tüm dünyaya örnek olurken, Avrupa'da, KOBİ'lerin büyümelerini finanse etmek için özel ihtiyaçlarını değerlendiren Euronext iştiraki EnterNext, KOBI'leri destekleyerek en uygun finansman çözümünü bulmalarına ve Borsa'yı

\footnotetext{
* Bu çalışma Arș. Gör. Mehmet SAĞLAM'ın “Kurumsal Yönetim İlkeleri'nin ve Mali Performans Göstergelerin KOBI'lerin Performansına Etkisi: BİST Üzerine Bir Uygulama Üzerine Bir Uygulama" başlıklı yüksek lisans tezinden türetilmiştir.

${ }^{1}$ Arş.Gör., Siirt Üniversitesi, İktisadi ve İdari Bilimler Fakültesi, Merkez / SİlRT,

EMAIL: mehmetsaglam@siirt.edu.tr ORCID: 0000-0002-1848-2605

2 Prof. Dr.,Hacettepe Üniversitesi, İktisadi ve İdari Bilimler Fakültesi, Çankaya / ANKARA,

EMAIL: mbkaran@hacettepe.edu.tr ORCID: 0000-0002-3923-4598
} 
daha iyi kullanmalarına yardımcı olacak șekilde tasarlanmıștır. Ülkemizde de işletmelerin yüzde 99,77'sini oluşturan KOBİ'ler, toplam istihdamın yüzde 78'ini, toplam katma değerin yüzde 55'ini, toplam satışların yüzde 65,5'ini, toplam yatırımların yüzde 50'sini, toplam ihracatın yüzde 60,1'ini, toplam kredilerin yüzde 24'ünü gerçekleştirmektedir. (T.C. Bilim Sanayi ve Teknoloji Bakanlığı, 2012: 4) KOBİlerin sermaye piyasalarından daha fazla yararlanmalarını sağlamak amacı ile son 20 yıldır Borsa İstanbul (Eski adı, İMKB) kapsamında piyasalar açmak için çeşitli çalışmalar yapılmıştır.

Ancak, KOBİ'lerin finansmanında tüm dünyada önemli sorunlar vardır. Bu konuların başında firmalarla ilgili bilgilerin yeterince şeffaf olmaması nedeniyle bir asimetrik bilgi akışı ortaya çıkmaktadır. Bu nedenle, yatırımcıların ilgilendikleri firmalar ile ilgili bilgilerinin tam olarak gerçeği yansıtmaması riski ortaya çıkmakta ve yatırımcı , "Ahlaki Tehlike " ve "Yanlış Seçim" problemleri ile karşı karşıya kalmaktadır. Bu sorunlar özellikle, potansiyel yatırımcıların dış finansman sağladıkları projenin ne ölçüde kalitede olduklarını doğrulayamaması ve yanlıș bilgilere dayanılarak yapılan kötü yatırımlar nedeniyle ortaya çıkmaktadır (Berger \& Udell, 2002: 32). Nitekim borsa uzmanları yabancl ve büyük kurumsal yatırımcıların birçoğu, büyük KOBİ hisse senetleri ile ilgilenmediğini, bilgilerin daha sağlıklı olduklarını düşündükleri büyük şirketlere yöneldiklerini söylemektedir. (Oral, 2017). Bu durum KOBİ piyasasında bilgi asimetrisinin fazla olması ve yatırımcıların KOBİ'lerin finansal bilgilerine yeterince güvenmediklerinden kaynaklanmaktadır. KOBİ'ler kurumsal yönetime ağırlık vererek şeffaflaştıkça, yatırımcıların güvenini kazanacak ve sermaye piyasasının olanaklarından daha fazla yararlanmaları mümkün olacaktır.

Küçük şirketlerde kurumsal yönetim ilkeleri konusunda en kapsamlı düzenlemeler, 2013 yılında İngiltere'de yapılmış ve The Quoted Companies Alliance (QCA) küçük şirketlerin uyması gereken Kurumsal Yönetim kodlarını yayınlamış ve birçok ülke onu takip etmiştir. Gelişmekte olan ülkelerdeki KOBI'lere yönelik olarak da International Finance Corporation (IFC) raporunda, genel olarak ailenin sahip olduğu işletmelerde ve KOBİ'lerde yöneticiortak probleminin ortaya çıkması daha az olmasına rağmen, şirketler ortak sayısını artırdıkça, onların çıkarlarını korumak için bazı mekanizmalar gerekebileceğinin altını çizmiş ve bir dizi prensip yayınlamıştır. Raporda, KOBİ'ler için, kurumsal yönetimin temel olarak iş verimliliğini ve performansını artırdığı ve denetim eylemlerinin azalttığ konulmuştur. (ACCA, 2015)

IFC'ye göre KOBİler için Kurumsal Yönetim açısından tek bir uluslararası standart bulunmamaktadır. Ancak aşağıdaki hususların onlar açısından önemli olduğunun altını çizmektedir (ACCA, 2015:5):

- Aile üyelerinin şirkette aldığı rol

- Farklı nesiller rol aldıkça gelişen aile kurumsal yönetim anlayışının geliştirilmesi

- Yönetim kurulunun (bağımsız üye dahil) rolü, yapısı ve dağılımı

- Üst düzey yöneticilerin işletme yönetimine etkisi ve bir CEO yönetim modelinin geliştirilmesi

IFC ayrıca bir Kurumsal Yönetim İlerleme Matrisi geliştirmiş ve bunun için öngördüğü en iyi dördüncü aşamaya ulaşmak için aşağıdaki uygulamaları esas almıştır. Bunlar;

- Kurumsal Yönetime olan bağlılık

- Yönetim kurulunun yapısı ve fonksiyonları

- Denetim ortamı ve süreçleri

- Şeffaflık ve kamuoyuna yapılan açılklamalar

- Azınlık hakları

IFC'ye göre bu koşullar gerçekleştiğinde, KOBI'lerin denetim maliyetlerinin ve risklerinin azalacağı, daha hızlı büyüyeceği ve finansal piyasalardan daha iyi yararlanacağı öne sürülmektedir. 
Ülkemizde ise kurumsal yönetim uygulamaları son on yıldır gelişmeye başlamıştır. Hala, KOBİ'lerin bilgi asimetrisinden doğan finansman sorunları katlanarak artmakta ve bu nedenle KOBİlerde kurumsal yönetimin yetersizliği önemli bir sorun olarak görülmektedir. Borsa İstanbul'un ana pazarlarında da işlem gören şirketlerinin birçoğunun küçük olması da bu problemi daha büyük bir hale getirmektedir. Bu nedenle 2003 yllından bu yana SPK, Borsa İstanbul şirketlerinin kurumsal yönetim ilkeleri kapsamında hareket etmeleri için teșvik etmektedir. SPK bu kapsamda şirket yönetimlerinin, paydaşlarla eşitlik, sosyal sorumluluk, şeffaflık, bağımsızlık, sorumluluk, disiplin ve hesap verebilirlik gibi temel yönetim unsurlarını gözeterek faaliyetlerini yürütmesini hedeflemektedir. Kurumsal yönetim ilkelerine uyum, payları Borsa İstanbul'da işlem gören şirketler açısından ihtiyari bir uygulama olmasına rağmen, bu şirketlerin yıllık faaliyet raporlarında ve internet sitelerinde Kurumsal Yönetim İlkeleri'ne uyum beyanlarına ve Kurumsal Yönetim Uyum Raporu'na yer vermelerini şart koşmaktadır.

Kurumsal yönetimin büyük ölçekli işletmeler üzerinde yarattığı olumlu ya da olumsuz etkilere dair çok sayıda çalışma bulunmakta iken, Kurumsal Yönetim İlkelerinin KOBİ'lerin mali performansı üzerindeki etkisine yönelik sınırlı sayıda çalışma vardır. Brunninge, Nordqvist, Wiklund (2007) KOBI'lerde strateji değişimi ve kurumsal yönetim mekanizması arasındaki ilişkiyi araștırmışlar ve örneklem olarak Amerika Birleşik Devletleri'ndeki 800'ün üzerinde KOBİ'yi incelemişlerdir. Bu çalışmada küçük işletmelerde kurumsal yönetim mekanizmalarının, onların strateji değiştirme yeteneklerini olumlu yönde etkilediğini ve onlar için çok önemli olduğunu ortaya koymuşlardır. Abor ve Adjasi (2007) Gana'daki KOBİ'leri örneklem olarak aldıkları çalışmada, kurumsal yönetimin dış bağımsız yöneticiler aracilığıla yeni stratejik görünüm getirdiği ve firmaların kurumsal girişimciliğini ve rekabetçiliğini arttırdığı ve Ganalı KOBI sektöründeki kredi sıkıntısı ve yönetimsel yetersizlik gibi sorunları da iyi bir kurumsal yönetim yapısıyla halledilebileceğini söylemişlerdir. Abor ve Biekpe (2007) yine Gana'daki KOBI'ler üzerinde yaptıkları çalışmada ise, kurumsal yönetim değişkenlerinden yönetim kurulu büyüklüğünün, yönetim kurulu yapısının, yönetim becerisinin seviyesi ve CEO'nun ikililiği (duality) kârlılığı önemli ölçüde olumlu yönde etkilediğini göstermektedir. Ayrıca, şirketin sahiplik yapısı, aile şirketi olup olmaması ve yabancı sahipliğgin varlığı da KOBİ'lerin karlılı̆̆ını olumlu etkilediğini neticesine ulaşmışlardır. Baldo (2012) yaptığı kalitatif çalışmada işletmelerin sosyal sorumluluklarının artmasında öncelikle girişimcinin değerlerine ve yönelimlerine ve ayrıca şirketin yerel sosyoekonomik çevreyle ne kadar iç içe olduğuna bağlı olduğunu dile getirmiştir. Ayrıca, kurumsal yönetim ilkelerinin KOBİ'lerin sosyal sorumluluklarını olumlu yönde etkilediğini belirtmiştir.

Ülkemizde Borsa İstanbul şirketleri üzerine birçok çalışma olmasına rağmen özel olarak kurumsal yönetim ilkelerinin KOBI'ler üzerine etkilerine bilimsel bir çalışma bulunmamaktadır. Bu nedenden dolayı çalışma, Türkiye literatürde bu alana ilişkin ilk çalışmalardan biridir. Bu çalışmanın temel motivasyonu, yatırımclar arasinda giderek daha fazla gelișen kurumsal yönetim bilincinin, KOBI'lerin mali performansında bir fark yaratıp yaratmadığını anlamaktır. Şüphesiz, yatırımcıların, KOBİ şirketlerinde kurumsala yönetim ile ilgili göstergelere daha fazla önem vermesi, kurumsal yönetim anlayışının güçlü olduğu KOBİ şirketlerinin sermaye piyasalarından daha fazla fon sağlamasına yol açabilecektir. Daha açık bir ifadeyle, bu çalışmada KOBİler, kurumsal yönetim anlayışlarını geliștirdikleri takdirde, yanlış seçim ve ahlaki tehlike risklerini azaltarak, GiP şirketlerine yönelen yatırımları artırıp artırılamayacağı yani GìP piyasasının işlem hacmine olan olumlu etkisi araștırılacaktır. 
$\mathrm{Bu}$ çalışmanın temel hipotezi, kurumsal yönetim ilkelerinin Borsa İstanbul'da işlem gören KOBİler üzerinde olumlu bir etkisinin olduğu yönündedir. Diğer bir ifade ile bu makalenin yanıtını aradığı soru, şirket yönetim ilkelerine ilişkin göstergelerin de finansal göstergeler kadar şirket performansı üzerinde etkili olup olmadığıdır.

Çalışmada, Borsa İstanbul'un KOBİ piyasalarında işlem gören 25 adet KOBİ'nin 2011'den 2017 yılına kadar olan 7 dönem boyunca 175 firma/yll esas alınmıştır. Çalışmada Borsa İstanbul'da işlem gören KOBİ'lerin veri seti kısıtlı olduğundan dolayı daha iyi sonuç alınabileceği düşünüldüğü için yöntem olarak Panel Veri Regresyon Analizi kullanılmış ve 4 adet model kurulmuştur.

Çalışma altı ana bölümden oluşmaktadır. Giriş bölümünden sonra ikinci bölümde, Borsa İstanbul ve KOBİ Piyasaları ile ilgili bilgiler verilmiş ve bu piyasalardaki kurumsal yönetim uygulamaları özetlenmiştir. Üçüncü bölümde Kurumsal Yönetim İlkeleri'nin finansal performansı etkilemesine yönelik literatürdeki çalışmalara yer verilmiştir. Dördüncü bölümde KOBİlerde kurumsal yönetim ilkelerinin finansal performanslarına etkisini ölçmeye yönelik ampirik bir çalışma yapılmış ve bulgular beşinci bölümde verilmiştir. $\mathrm{Bu}$ çalışmanın sonuçları altıncı bölümde ortaya konulmuştur.

\section{BORSA ÍSTANBUL KOBİ PIYASALARI VE KURUMSAL YÖNETIM UYGULAMALARI}

Borsa İstanbul, İstanbul Menkul Kiymetler Borsası ismi ile resmi olarak 3 Ocak 1986 yılında faaliyete geçmiş ve yaklaşık 30 yıldan fazla süredir ülkemizin en önemli piyasası olmasına rağmen en önemli sorunu, ortalama şirket büyüklüğü açısından oldukça küçük olmasıdır. (Ceyhan, 2014). Buna rağmen faaliyete geçtikten sonra özellikle büyüme potansiyeli olan küçük ve orta ölçekli işletmelere büyük önem vermiştir. Bu kapsamda ilk piyasasını 1995 yılında Hisse Senedi Piyasasının altında "Yeni Şirketler Pazarı" adı ile kurduktan sonra, bu piyasanın ismini "Yeni Ekonomi Pazarı" olarak değiştirmiş ve bu pazara özellikle getirdikleri teknoloji ile ciddi bir büyüme potansiyeli olan şirketleri kabul etmeye başlamıştır. 2009 yılında ise borsada kotasyon koşullarını sağlayamayan gelişme ve büyüme potansiyeline sahip KOBI'lerin sermaye piyasalarından fon sağlaması amacıyla Borsa İstanbul bünyesinde ayrı bir Pazar kurarak adını "Gelişen İşletmeler Pazarı" olarak koymuştur. $\mathrm{Bu}$ piyasadaki işletmeler Pazar yapıcıların olup olmamasına bağlı olarak sürekli veya tek fiyat ișlemi ile müzayedeye tabi tutulacaklardı. Bu şirketlerin halka açık piyasa değeri 25 Milyon TL'nin altında olup, Gelişen İşletmeler Pazarıdır (GİP). 2 yıl süreyle işlem gördükten sonra, şirketler Yıldız ve Ana Pazara geçiş başvurusu yapabilirler. 2013 yılında ise KOBİ'lere yönelik en önemli adım KOBİ Sanayi Endeksinin hesaplanmasıdır. 1 Ekim 2010 tarihinden itibaren; Borsa İstanbul'da işlem gören hisse senetleri SPK tarafından belirlenen kriterlere göre A, B, C ve D Gruplarına ayrılarak işlem görmeye başlamıştır. Bu kriterlerin en önemlisi fiili dolaşımdaki pay değerinin büyüklügüdür, Gelişen işletmeler pazarında yer alan işletmeler D grubunda olup kredili alım veya açığa satış işlemlerine konu olamazlar. (Borsa İstanbul, 2014)

Gelişen İşletmeler Pazarı'nda mevcut 25 şirket vardır ve bu şirketler hemen hemen her sektörde faaliyet göstermektedir. İşlem gören KOBİ'lerin aktif varlıkları toplamı en az 5,8 milyon Türk Lirası, net satış gelirleri ise en az 11,6 milyon Türk Lirası olan sermayeleri paylara bölünmüş şirket statüsünde olması gerekir. Bu sınırlamalara ek olarak şirketlerin halka arz edilen paylarının değeri de 25 milyon Türk Lirası'ndan az olmak zorundadır. (Borsa İstanbul, 2016)

Türkiye, kurumsal yönetim açısından Enron olayı ile başlayan küresel gelişmeleri yakından incelemiştir. İlk olarak TÜSİAD'ın gayretleriyle 2001 yllında "Kurumsal yönetim: En iyi uygulama kodu" rehberini hazırlamıştır. 2003 yılına gelindiğinde Sermaye Piyasası Kurulu tarafindan "Sermaye Piyasası Kurulu Kurumsal Yönetim İlkeleri” adlı çalışma yayınlanmıştır. 
(TKYD, 2011: 21-22). Literatürde "Uygula ya da açıkla" olarak geçen prensip 2004 yılında ilgili kanun maddesinde beyan zorunluluğu olarak gösterilirken, 2005 yılında bu beyanların "Kurumsal Yönetim Uyum Beyanları" adı altında şirketlerin yıllık faaliyet raporlarında gösterilmesi mecburi kılınmıștır. (TKYD, 2011: 22). 2015 yllına gelindiğinde yine ülke gündemimizde yer kaplayan kurumsal yönetim hususu, ülkemizin dönem başkanlığında gerçekleşen G20 zirvesinin bir parçası olarak Ankara'da düzenlenen toplantı neticesinde "G20/OECD Kurumsal Yönetim İlkeleri” olarak kabul edilmiștir. (TKYD, 2011: 48)

Borsa İstanbul'da işlem gören şirketlerin kurumsal yönetim uygulamalarına teşvikinin sağlanması, onların bu ilkeleri benimsemesi ve pay piyasasının gelişmesi amacıyla Kurumsal Yönetim Endeksi oluşturulmuştur. (Dağll, Ayaydın, \& Eyüboğlu, 2010: 22) Ayrıca bu endeks "Borsa İstanbul Kurumsal Yönetim Endeksi Temel Kuralları" çerçevesinde şirketin fiyat ve kazanç performanslarının ölçülmesi amacina hizmet etmektedir. (Denetimnet, 2018: 1)

Kurumsal Yönetim Endeksi, Borsa İstanbul'da işlem gören şirketlerin kurumsal yönetim ilkelerine uyum notuna göre oluşturulmuştur. $\mathrm{Bu}$ endekste yer alabilmek için kurumsal yönetim uyum notu olarak 10 üzerinden en az 7 alınması ve her ana başlık için ise en 6,5 olması gerekir. (Borsa İstanbul, 2018: 1)

\section{LITERATÜR TARAMASI}

Literatürde, uygulamalarının

\section{performansina etkisiningenel ola}

yönetim finansal

performansına etkisinin genel olarak bir netlik kazanmadığı, fakat bununla birlikte olumlu sonuçların daha baskın olduğu görülmektedir. Bazı çalışmalarda hiç sonuç bulunamazken, bazılarında ise sonuçların olumsuz olduğu kayda değer ölçüde mevcuttur.

Rechner ve Dalton (1991) etkili kurumsal yönetim ilkelerinin olduğu bağımsız liderlik yapısını seçen firmaların, CEO'nun ikiliğini benimseyen firmalardan tutarlı bir şekilde daha üstün performansa sahip olduğunu tespit etmişlerdir. Hambrick ve Fukutomi (1991)'ın yaptıkları çalışmada ise, CEO'nun görev süresinin firmanın performansını etkileyebileceğini, bu yüzden CEO'nun görev süresinin firmalar için önemli bir parametre olduğunu dile getirerek, CEO'nun görev süresinin dinamikleri üzerine bir model oluşturmuşlardır. Bu modele göre CEO'nun görev sırasındaki pozisyonunda fark edilebilir aşamaların olduğunu, farklı aşamalarda yöneticilerin dikkat düzeylerinin ve davranışlarının farklılaştığını bu da firmanın performansını etkilediğini dile getirmişlerdir. Yermack (1996) çalışmasında ise, küçük yönetim kuruluna sahip olan şirketlerin daha etkili performansa sahip olduğunu ortaya çlkarmıştır. Ayrıca küçük yönetim kurullarının daha iyi finansal oranlar ve daha güçlü icra kurulu başkanı performansı için elverişli olduğunu tespit etmiştir. Miller ve Shamsie (2001) ile yaptıkları araştırmalarda CEO'nun görev süresinin firma performansını etkilediğini, fakat bu etkinin $U$ şeklinde olduğunu yani ilk zamanlar firma performansını artırırken daha sonraları firma performansında düşme etkisi yarattı̆̆ını söylemişlerdir. Drobetz, Schillhofer ve Zimmernann (2004) çalışmalarında kurumsal yönetim seviyesiyle firma değeri arasında doğru orantılı bir ilişki olduğunu tespit etmişlerdir. Bhat, Hope ve Kang (2006) kurumsal yönetimin şeffaflık ilkesinin finansal tahminlerle pozitif ilişkiye sahip olduğu bulmuşlardır. Simsek (2007) ise CEO'nun uzun süre görevde kalması diğer üst yöneticileri direkt olarak etkilemekte olduğunu bu da firmaların risk alma seviyelerinde değişiklik yarattığını söyleyerek ve CEO'nu görevde kalma süresi firmanın performansını dolaylı yoldan etkileyebileceğini belirtmiștir. Kurumsal yönetim ilkeleri ve firma değeri arasındaki ilişkiye bakan Ammann, Oesch ve Schmid (2011), firma değeri ile firmanın kurumsal yönetim seviyesinin doğru orantılı ve güçlü bir ilişkiye sahip olduğunu dile getirmişlerdir. Fidanoski, Mateska ve Simeonovski (2013) yaptıkları çalışmada yönetim kurulu büyüklügünün aktif karlılık ve 
öz sermaye karlılığı ile doğru orantılı bir ilișkisi olduğunu söylemişlerdir. Aghabaki (2014) şirketin kurumsal yönetim endeksinin öz sermaye net karlılığını olumlu etkilerken, hisse getiri oranını ise negatif etkilediğini belirtmiştir. Al-Najjar (2014) çalışmasında yönetim kurulundaki bağımsız üye sayısının şirket ve hisse performansıyla pozitif ilişkiye sahip olduğunu belirlemiştir. Geniş yönetim kurullarının şirket karını arttırdığını, küçük yönetim kurullarının ise daha etkili hisse performansı sağladığını açıklamıştır. Ayrıca yönetim kurulu büyüklüğü ve bağımsız üye sayısının finansal performansa (ROA ve ROE) olumlu etki yaptığını belirtmiştir. Ararat, Black ve Yurtoğlu (2017) kurumsal yönetimle firma değeri arasında güçlü bir ilişkinin mevcut olduğunu dile getirmişlerdir.

Kerr ve Bettis (1987) Yönetim kurullarının şirketin hisse performansını izleyerek yönetim performansı hakkında hüküm vermesinin anlamlı olmadığını ve yetersiz bir kıstas olduğunu belirtmişlerdir. Fizel ve Louie (1990) CEO’ların sahip oldukları güç nedeniyle hissedarlara karşı sorumlu oldukları hesap verilebilirlik ilkesinin sınırlandığını vurgulamışlardır. Bağımsız yönetici ile şirketin uzun dönem performansını karşılaștıran Bhagat ve Black (1998) bağımsız yönetici oranı arttıkça şirketin finansal performansının artmadığını, aksine ters orantılı bir seyir izleyerek şirketin düşük karlılık gösterdiğini analiz etmişlerdir. Kurumsal yönetim ilkeleri ve firma performansı arasındaki ilişkiyi araştırdıkları bir başka çalışmada ise, Bhagat ve Black (2008) yönetim kurulu üyelerinin hisse senedi sahipliği ve CEO'nun ikililiği (duality) ile firmanın faaliyet performansı arasında doğru yönlü bir bağlantı bulmuşlardır. Mashatekhi ve Bazaz (2008) ise, yönetim kurulu büyüklügü ile firma performansı arasında negatif bir ilişki bulmuşlardır. Bağımsız yöneticiler firma performansını güçlendirirken, liderlik yapısı ile firma performansı arasında bir ilișkinin bulunmadığını açıklamışlardır. Adams ve Ferreira (2009) yönetim kurulunda cinsiyet çeşitliliği olan şirketlerde kurulların denetim rolünün daha fazla olduğunu ve şirket performansını ortalama açıdan negatif etkilediğini belirtmişlerdir. Aebi, Sabato ve Schmid (2012) 2008 kriz döneminde standart kurumsal yönetim uygulamalarının banka performansıyla ilişskisinin önemsiz, hatta düşünülenin aksine negatif yönlü olduğunu belirtmişlerdir. Bu çalışmayı destekler nitelikte olan Erkens, Hung ve Matos (2012) 'un yaptığı araştırmada ise, kurumsal yönetim ilkelerinin kriz döneminde şirketin firma performansına etkisine baktıklarında bağımsız üye sayısı fazla ve kurumsallığ şirketlerin daha kötü hisse getirisi gösterdiklerini söylemişlerdir. Vintila ve Paunescu (2016) yönetim kurulu büyüklüğü ve bağımsız yönetici oranı ile CEO'nun ikililiği arasında ise negatif bir etkinin varlığını belirtmişlerdir. Son olarak da, Miller ve Yang (2015) CEO'nun hem yönetim kurulu bașkanı hem de şirketin tepe yöneticisi olarak görev yapmasının işletme performansına olan etkisi incelemişlerdir. Fakat inceleme sonucu bu durumun şirket performansına zararı olduğuna dair herhangi bir delil bulamamışlardır.

Kurumsal Yönetim konusunda, Türkiye'de yapılmış çok sayıda çalışma vardır. Ancak bu çalışmaların hiçbiri özel olarak Borsa İstanbul KOBİ şirketlerini hedeflememiştir. Bu konudaki çalışmalar 2010 yılından itibaren daha çok görülmeye başlanmıştır. Arslan, Karan ve Ekşi (2010), CEO' nun ikililiği (duality) firmanın mali performansına etkisinin olmadığını, fakat kriz zamanlarında negatif etkisi olduğu belirtmişlerdir. Ayrıca bağımsız yöneticilerin mali performansa etkisi olmadığı neticesini bulmuşlardır. Sakarya (2011) kurumsal yönetim skorları iyi olarak açıklanan şirketlerle hisse getirileri arasında doğru orantılı bir ilişki olduğunu bulmuştur. Bankalarda kurumsal yönetim ve entelektüel sermaye ilişkisini araştıran Yılmaz (2011), bankalar için kurumsal yönetim uygulamalarının rekabet edebilmek için önemli bir araç haline geldiğini söylemiștir. Balkan (2014) ise kurumsal yönetim seviyesi arttıkça öz sermeye karlılığının da arttığını söylemiştir. Yasan (2016), KOBİlerde yönetim kurulu olanların olamayanlara göre daha güçlü performans 
gösterdiği ve kaynak yaratma kabiliyetlerinin daha iyi olduğu sonucuna ulaşmıștır. Yılmaz (2016) , kurumsal yönetim ilkelerinin finansal performans göstergeleri ile ilişkisinin anlamlı ama zayıf bir yapı içerisinde olduğunu söylemiştir.

\section{VERİ VE YÖNTEM}

Çalışmada, hisseleri Borsa İstanbul'da işlem gören KOBİler alınmıștır. Bu bağlamda sadece Gelișen İşletmeler Pazarı'nda işlem gören bu 25 KOBİ ve daha sonra bu pazardan bir üst pazara geçen şirketler alınmıştır. Çalışmada veri seti olarak KOBİ piyasasında şirket sayllarının yüksek olduğu dönem dikkate alınarak, 2011'den 2017 yllına kadar olan 7 dönemlik 175 firma yılı kullanılmıştır. KOBİ'lere ilişkin finansal ve kurumsal yönetim uygulamaları ile ilgili bazı veriler Kamuyu Aydınlatma Platformu'nun (KAP) internet sitesinden alınmıștır. Diğer veriler ise "Thomson Reuters Eikon" veri merkezinden elde edilmiştir. Verilerin temel alınmaya başlandığı zaman diliminin 2011 yılı ile başlamasının sebebi, KOBİ piyasasındaki çoğu şirketin bu tarihten itibaren borsaya kota olmaya bașlaması ve bununla birlikte bu tarihten itibaren faaliyet raporlarını kamuyu aydınlatma platformunda yayınlamalarıdır.

Birçok çalışmada şirketler için finansal gösterge olarak kullanılan 2 bağımlı değişken ile kurumsal yönetim ölçülmesine ilişkin kullanılan 5 bağımsız değişken ve 5 kontrol değişkeni seçilmiştir. Seçilen bu değişkenlerle 4 farklı model kurulacaktır. İlk iki modelde sadece bağımsız değişken olarak kurumsal yönetim ilkeleri alınırken, diğer iki modelde firmaların mali tablolarından elde edilen kontrol değişkenleri kullanılmıştır. Buradaki amaç kontrol değişkenli ve kontrol değişken eklenmeden yapılan analizler sonucunda KOBİ'lerin finansal performansını etkileyen baskın bir değişken olup olmadığını ortaya çıkarmaktır. Araştırmada kullanılan bağımsız değişkenlerin seçiminde daha önce kurumsal yönetim alanında yapılan araştırmalarda kullanılan verilerden yararlanılmıștır. $\mathrm{Bu}$ modellerde bağımlı değişken olarak Bhagat ve Black (2000), Cheng (2008), Haniffa ve Hudaib (2006) ve birçok araştırmacıdan faydalanılarak, Aktif Karlılık Oranı (AKO) ile Öz Sermaye Karlılık Oranı (OKO) kullanılmıştır. $\mathrm{Bu}$ çalışmada kullanılan değișkenlerin hepsi, benzer çalışmalarda da modellere girdi olarak kullanılmıştır. Tablo 1'de bu çalışmada kullanılan değişkenlerin tanımı ile kullanıldığı önceki çalışmaların listesi verilmiştir.

Bağımsız değişken seçiminde de literatüre bağlı kalınmıştır. Çalışmamızda kullanılan kurumsal yönetim oranlarından CEO'nun Görevde Bulunduğu Süre (GBS), nin firma performansını olumlu bir yönde etkilemesi beklenmektedir (Hambrick ve Fukutomi,1991). Diğer taraftan bazı çalışmalar CEO'nun hem yönetim kurulu başkanı hem de genel müdür olmasının firma performansını azalttığını ortaya koyarken (Rechner ve Dalton, 1991), bazı çalışmalar da aksini öne sürmektedir (Bhagat ve Black, 2008). Yönetim kurullarında bağımsız üye ve kadın üye bulundurulmasının, firma performansını etkilediğini ortaya koyan birçok çalışma vardır (Bkz. Tablo 1). Ayrıca aynı tabloda yönetim kurulu büyüklüğü ile firma performansı arasında bir ilişki olduğunu gösteren çalıșmalar da sıralanmıștır. Ararat, Black ve Yurtoğlu (2017) dış satış oranının ve Mashayeki ve Bazaz (2008), Bhagat ve Bolton (2008), ile Erkens, Hung ve Matos (2012) firma büyüklüğü gibi kontrol değişkenlerinin firmaların kurumsal yönetim uygulamalarını etkilediklerini ortaya koymuşlardır.

$\mathrm{Bu}$ çalışmada ayrıca bazı finansal oranları da kontrol değişkeni olarak kullanılmıștır. Bunlar; dönen varlıklardan stokların çıkarılıp kısa vadeli yabancı kaynaklara bölünmesiyle bulunan Asit-Test Oranı (ATO), hazır değerler ile menkul kıymetlerin kısa vadeli yabancı kaynaklara bölünmesiyle bulunan Nakit Oranı (NO) değerleridir.

Verilerin tanımlayıcı istatistikleri tablo halinde aşağıdaki gibidir: 
Tablo 1. Araștırmada Kullanılan Verilerin Tanımı ve Kullanıldığı Önceki Çalıșmalar

\begin{tabular}{|c|c|}
\hline Değişkenler & Değişkenlerin Yer Aldığı Çalışmalar \\
\hline $\begin{array}{c}\text { Aktif Karlılık Oranı (AKO) } \\
\text { N. Kar/T.Aktif }\end{array}$ & $\begin{array}{l}\text { Bhagat ve Black (2000), Haniffa ve Hudaib (2006), Bhagat ve Bolton (2008), Mashayeki } \\
\text { ve Bazaz (2008),Cheng (2008), Karamustafa, Varıcı ve Er (2009), Bhagat, Bolton ve } \\
\text { Subramanian (2010), Fidanoski, Mateska ve Simeonovski (2013), Al-Najjar (2014), } \\
\text { Yılmaz (2016) ve Vintila \& Paunescu (2016) }\end{array}$ \\
\hline $\begin{array}{l}\text { Öz Sermaye Karlılık Oranı } \\
\text { (OKO) } \\
\text { N. Kar/Öz sermaye }\end{array}$ & $\begin{array}{l}\text { Drobetz, Schillhofer ve Zimmermann (2003), Mashayeki ve Bazaz (2008), Karamustafa, } \\
\text { Varıcı ve Er (2009), Fidanoski, Mateska ve Simeonovski (2013), Al-Najjar (2014) ve } \\
\text { Vintila \& Paunescu (2016) }\end{array}$ \\
\hline $\begin{array}{c}\text { EO'nun Görevde Bulunduğu } \\
\text { Süre (GBS) }\end{array}$ & $\begin{array}{l}\text { Fizel ve Louie (1990), Hambrick ve Fukutomi (1991) Molz (1995), Denis ve Sarin } \\
\text { (1999), Arthur (2001), Miller ve Shamsie (2001), Baker ve Gompers (2003), Boone, } \\
\text { Field, Karpoff ve Raheja (2007), Cheng (2008), Coles, Daniel ve Naveen (2008) Pathan } \\
\text { ve Skully (2010), Bhagat, Bolton ve Subramanian (2010), Khan ve Vieto (2013), Miller } \\
\text { ve Yang (2015) }\end{array}$ \\
\hline CEO & $\begin{array}{l}\text { Molz (1995),Mak ve Li (2001),Grinstein ve Valles (2008), Linck, Netter ve Yang (2008) } \\
\text { Mashayeki ve Bazaz (2008), Bhagat ve Bolton (2008), Pathen ve Skully (2010) , Dey, } \\
\text { Engel ve Liu (2011) ,Erkens, Hung ve Matos (2012), Miller ve Yang (2015) }\end{array}$ \\
\hline $\begin{array}{l}\text { Yönetim Kuı } \\
\text { Bağımsız Or }\end{array}$ & $\begin{array}{l}\text { Molz (1995) ,Mak ve Li (2001), Arthur (2001), Baker ve Gompers (2003), } \\
\text { Kanagaretham, Lobo ve Whalen (2007), Boone, Field, Karpoff ve Raheja (2007), } \\
\text { Grinstein ve Valles (2008), Linck, Netter ve Yang (2008) Mashayeki ve Bazaz (2008), } \\
\text { Bhagat ve Bolton (2008),Guest (2009) Pathen ve Skully (2010), Dey, Engel ve Liu (2011) } \\
\text {,Erkens, Hung ve Matos (2012), Miller ve Yang (2015) }\end{array}$ \\
\hline $\begin{array}{l}\text { Yönetim Kurul } \\
\text { Yöneticilerin }\end{array}$ & e Ferreira (2009) ve Vintila \& Pa \\
\hline $\begin{array}{c}\text { Yönetim Kurulu Büyüklüğü } \\
\text { (YKB) }\end{array}$ & $\begin{array}{l}\text { Yermack (1996) ,Arthur (2001), Hillier ve McColgan (2006), Haniffa ve Hudaib, Lasfer } \\
\text { (2006), Kanagaretham, Lobo ve Whalen, (2007), Boone, Field, Karpoff ve Raheja (2007), } \\
\text { Mashayeki ve Bazaz (2008), Guest (2009), Adams ve Ferreira (2009), Beekes, Hong ve } \\
\text { Owen (2010) Pathen ve Skully (2010), Al-Najjar (2014),Miller ve Yang (2015), }\end{array}$ \\
\hline Jaur & Ararat, Black ve Yurtoğlu (2017) \\
\hline İşletn & ng ve Matos (2012) \\
\hline
\end{tabular}

Tanımlayıcı istatistiklere göre Gelişen İşletme Pazarı'nda işlem gören KOBİ'ler genel olarak kaynaklarını verimli kullanmadıkları görülmektedir. Fakat oranı düşük olsa da şirketlerin mali rantabiliteleri ortalama olarak pozitiftir. Şirketlerin ortalama likidite oranları iyi durumdadır ve borçlarını ödeme konusunda sıkıntı yaşamamaktadırlar. Ancak likidite oranlarında yüksek standart sapma olduğundan bazı KOBİler için bu durumun geçerli olmadığı görülmektedir. İşletmelerin yaptıkları satışlarda ihracatın oranı ortalama olarak \%13 tür, bu da dış satışlarının ne kadar az olduğunun göstergesidir. Yönetim kurullarında her beş yöneticiden birisi kadındır ve CEO’ların görevde kalma süreleri kısadır.

Tablo 2: Modelde Kullanılan Değișkenlerin Tanımlayıcı İstatistikleri

\begin{tabular}{|c|c|c|c|c|c|c|c|c|}
\hline Değişken & Ort & Med. & Maks. & Min. & S. Sap. & Çarpık. & Basıklık & Gözlem \\
\hline AKO & 0,01 & 0,01 & 0,47 & $-1,6$ & 0,16 & $-5,17$ & 52,91 & 172 \\
\hline OKO & $-0,01$ & 0,02 & 1,25 & $-2,04$ & 0,32 & $-2,32$ & 15,97 & 172 \\
\hline DUA & 0,65 & 1 & 1 & 0 & 0,47 & $-0,67$ & 1,44 & 173 \\
\hline BS & 0,13 & 0 & 0,5 & 0 & 0,18 & 0,63 & 1,44 & 173 \\
\hline GBS & 12 & 10 & 31 & 1 & 8,95 & 0,46 & 1,96 & 169 \\
\hline KDO & 0,2 & 0,2 & 0,80 & 0 & 0,20 & 0,63 & 2,60 & 173 \\
\hline YKB & 1,45 & 1,60 & 2,19 & 1,09 & 0,26 & $-0,28$ & 1,84 & 173 \\
\hline TA & 17,08 & 17,18 & 19,44 & 15,09 & 0,92 & 0,12 & 2,87 & 172 \\
\hline ATO & 2,49 & 1,14 & 96,79 & 0,08 & 8,50 & 9,512 & 98,58 & 172 \\
\hline DSO & 0,13 & 0,03 & 1,17 & 0 & 0,21 & 2,27 & 8,81 & 171 \\
\hline NO & 0,57 & 0,06 & 38,95 & 4,81 & 3,03 & 11,95 & 151,30 & 172 \\
\hline
\end{tabular}


Borsa İstanbul'da işlem gören KOBİlerin kurumsal yönetim uygulamalarının finansal performansını ne ölçüde etkilediğini bulmak için en uygun model olarak panel veri regresyon yöntemi kullanılacaktır. Finansal performans analizlerinde hem zamana hem de birimlere göre bilgi elde etmek için panel veri kullanılmalıdır. (Tatoğlu, 2012: 3) Panel veri veya diğer adıyla uzunlamasina veri, değişkenlerin iki veya daha fazla zaman dilimlerinde gözlenebildiği çok birimli veridir. (H.Stock \& W.Watson, 2011: 13) Panel veri setiyle kurulan modeller yardımıyla ekonomik ilişkilerin tahmin edilmesi yöntemine panel veri analizi denilmektedir. Her birim tüm zaman dilimlerinde gözlenmişse dengeli panel veri, tam olarak gözlenmemişse dengesiz panel veri olarak sinıflandırılır. (Tatoğlu, 2012: 5) Çalışmada dengesiz panel veri kullanılmıştır.

Bu çalışmada, model kurulurken model olarak sabit etkiler (fixed effect) ya da rassal etkiler (random effects) modellerinden yararlanılmıştır.

Çalışmada aktif karlılık ile öz sermaye karlılığının bağımlı değişken olduğu dört tane panel regresyon modeli kurulmuştur. Değişkenler aralarındaki korelasyon değerleri 0,50'den düşüktür. Fakat yine de değişkenlerin arasındaki ilişki 0,50'nin altında olsa bile çoklu bağlantı sorunu modelde olabilmesi mümkün olduğundan, çoklu bağlantının tespiti için bağımsız değișkenlerin VIF değerlerine (variance inflation factors - VIF) bakılması tavsiye edilmektedir (Gujarati, 2004: 359). VIF değerleri Gujarati (2004) 'ye göre 10'dan küçük ve açıklayıcı oranı 0,90’nı aşamamışsa sıkıntı olmayacaktır. Fakat yazın incelemesindeki çoğu çalışmada VİF değerinin 5'in altında olmasının daha iyi olacağ söylenmiștir. Varyans şişirme faktörleri ${ }^{3}$ değerlerinin hepsi 5'in altında çıkmıştır (Gujarati, 2004: 374).

Bhagat ve Bolton (2008), Masheyekhi ve Bazaz (2008), Fidanoski, Mateska ve Simeonovski (2013), Yllmaz (2016) ve Vintila \& Paunescu
(2016) çalışmalarından yararlanılarak oluşturulan ve araștırmada tahmin edilecek panel regresyon modelleri aşağıdaki gibi kurulmuştur:

Yalnız kurumsal yönetim değişkenleri ile kurulan modeller:

\section{Model 1}

$\mathrm{AKO}_{\text {it }}=\theta+\beta_{1} \mathrm{GBS}_{\mathrm{it}}+\beta_{2} \mathrm{KDO}_{\mathrm{it}}+\beta_{3} \mathrm{BS}_{\mathrm{it}}+$ $\beta_{4} \mathrm{YKB}_{\text {it }}+\varepsilon_{\text {it }}$

\section{Model 2}

$\mathrm{OKO}_{\text {it }}=\theta+\beta_{1} \mathrm{GBS}_{\mathrm{it}}+\beta_{2} \mathrm{KDO}_{\mathrm{it}}+\beta_{3} \mathrm{BS}_{\mathrm{it}}+$ $\beta_{4} \mathrm{YKB}_{\text {it }}+\varepsilon_{\text {it }}$

Kurumsal yönetim değişkenleri ve kontrol değişkenleri ile kurulan modeller:

\section{Model 3}

$\mathrm{AKO}_{\text {it }}=\theta+\beta_{1} \mathrm{GBS}_{\mathrm{it}}+\beta_{2} \mathrm{KDO}_{\mathrm{it}}+\beta_{3} \mathrm{BS}_{\mathrm{it}}+$ $\beta_{4} \mathrm{YKB}_{\text {it }}+\beta_{5} \mathrm{DSO}_{\text {it }}+\beta_{6} \mathrm{TA} \mathrm{A}_{\text {it }}$

$+\beta_{7} \mathrm{ATO}_{i t}+\beta_{8} \mathrm{NO}_{i t}+\varepsilon_{i t}$

\section{Model 4}

$\mathrm{OKO}_{\text {it }}=\theta+\beta_{1} \mathrm{GBS}_{\text {it }}+\beta_{2} \mathrm{KDO}_{\text {it }}+\beta_{3} \mathrm{BS}_{\mathrm{it}}+$ $\beta_{4} \mathrm{YKB}_{\text {it }}+\beta_{5} \mathrm{DSO}_{\text {it }}+\beta_{6} \mathrm{TA}_{\text {it }}$

$+\beta_{7} \mathrm{ATO}_{i t}+\beta_{8} \mathrm{NO}_{i t}+\varepsilon i t$

Panel veri analizi yöntemi kullanılırken testin doğrulunu sağlamak için değişkenlere bir takım testler uygulanır, aksi takdirde modelin sonucu yanlış çıkabilmektedir. Bu yöntem kullanılırken karşılaşılan sorunlar genellikle zaman serilerinde görülen sorunlarla aynıdır. (Tatoğlu, 2012: 199) Bu sorunlardan ilki serilerin durağan olup olmaması yani birim köke sahip olmasıdır. Granger ve Newbold (1974) yaptıkları çalışmada seriler durağan olmadığı zaman (birim köke sahipse) tahmin edilen modelin sahte regresyon olabileceğini bunun da modeldeki katsayıların sonuçlarının etkisiz, denklemdeki tahminlerin en düşük seviye ve kat sayıların güvenilirlik testlerinin yanlış olmasına sebep olacağını söylemişlerdir. (Granger \& Newbold, 1974: 1)Modelin tahminin sağlıklı sonuçlar vermesi için

3 Varyans şişirme faktörleri, Eviews 8.1 ekonometrik analiz programıyla ölçülmüştür. 
verilerin durağanlığının ölçülmesi gerekmektedir. Durağanlığı sınamak için geliştirilen testlerden birisi son yllarda popüler hale gelen birim kök testidir. Maddala ve $\mathrm{Wu}$ (1999), dengeli olmayan panel için Fisher testinin daha iyi olduğunu söylemiștir. (Maddala \& Wu, 1999: 636)Bu yüzden birim kök sınaması için Fisher tabanlı Phillips-Perron (PP) testi kullanılacaktır. PP testi için hipotezler şöyledir;

H0: Seri durağan değildir (Birim kök içerir)

H1: Seri durağandır (Birim kök içermez)

Newey-West bant genişliği için Bartlett Kernel'in kullanıldı̆̆ sonuçları\% 1 ya da \% 5 anlamlılık düzeyinde sabitli ve sabitli-trendli olarak Tablo 3'de verilmiştir. ${ }^{4}$

Modelde yararlanılacak olan verilerden GBS, DUA, KDO, BS ve YKB dışındaki tüm değişkenler $\% 1$ ya da \% 5 anlamlılık düzeyinde ve I(0) seviyesinde durağandır. GBS, KDO, BS ve YKB değişkenlerinin 1. derece farkları alınarak I(1) durağanlaştırılmıștır. DUA değişkeni ise 2 . derece farkı alınsa da durağanlaşmamıştır, bu yüzden modelden çıkarılmıştır.

Tablo 3: Birim kök test sonuçları

\begin{tabular}{|l|l|l|l|l|}
\hline \multirow{2}{*}{ Değişkenler } & \multicolumn{3}{|l|}{ PP- Fisher Ki-Kare } & $\begin{array}{l}\text { PP- Fisher Ki-Kare } \\
\text { derece farkı } \\
\text { alındıktan sonra } \\
\text { (Olasılık-p) }\end{array}$ \\
\hline & (Olasılık-p) & $\begin{array}{l}\text { Sabitli } \\
\text { Trendli }\end{array}$ & Sabitli & $\begin{array}{l}\text { Trendli } \\
\end{array}$ \\
\hline Sabitli & 0,0000 & 0,0000 & 0,0000 & 0,0000 \\
\hline OKO & 0,0000 & 0,0000 & 0,0000 & 0,0000 \\
\hline GBO & 0,8390 & 0,5764 & 0,0763 & 0,0127 \\
\hline DUA & 0,9528 & 0,3896 & - & - \\
\hline KDO & 0,5920 & 0,3588 & 0,0028 & 0,0000 \\
\hline BS & 0,3164 & 0,5491 & 0,0017 & 0,0000 \\
\hline YKB & 0,3994 & 0,9912 & 0,0215 & 0,0000 \\
\hline DSO & 0,0000 & 0,0006 & 0,0000 & 0,0006 \\
\hline TA & 0,0000 & 0,0000 & 0,0000 & 0,0000 \\
\hline ATO & 0,0042 & 0,0000 & 0,0042 & 0,0000 \\
\hline NO & 0,0000 & 0,0000 & 0,0000 & 0,0000 \\
\hline
\end{tabular}

Modelin sabit mi yoksa tesadüfi etkiler mi olduğuna karar vermek için Hausman (1984) testi yapılacaktır. $\mathrm{Bu}$ testin $\mathrm{HO}$ hipotezi

${ }^{4}$ Birim kök testi Eviews 8.1 ekonometrik analiz programı yardımıyla yapılmıştır. "tesadüfi etkiler modeli sabit etkiler modelinden daha iyidir" șeklindedir. Kurulacak dört model için Hausman test sonuçları şöyledir:

Tablo 4: Hausman Test Sonuçları

\begin{tabular}{|c|c|c|c|}
\hline & İstatistik & $\begin{array}{c}\text { Serbestlik } \\
\text { Derecesi }\end{array}$ & Olasılık \\
\hline Model-1 & 3,376281 & 4 & 0,4969 \\
\hline Model-2 & 3,121317 & 4 & 0,5377 \\
\hline Model-3 & 12,870684 & 8 & 0,1164 \\
\hline Model-4 & 10,753077 & 8 & 0,2161 \\
\hline
\end{tabular}

Her dört modelde de boş hipotez reddedilemediği için modeller tesadüfi etkilere göre kurulacaktır.

Panel veri modellerinde karşılașılan diğer bir sorun zaman serilerinde de sıkça görülen oto korelasyon problemidir. (Kutlar, 2007: 181) Modelde oto korelasyon sorununun olup olmadığına bakmak için Durbin - Watson (DW) istatistiği kullanılacaktır. Durbin - Watson'un \%5 anlamlılık düzeyinde değişken sayısına göre hazırladığı tablodaki en yüksek ve en düşük istatistik değeri denklemde yerine koyulduğu zaman 2'ye yakın değerlerde oto korelasyondan bahsedilemez. (Kutlar, 2007: 189-190)

Her dört modelde de DW istatistiği 2'ye yakın değerler çıkmıştır ve modellerde oto korelasyon sorunu olmadığı gözlenmiștir. Panel verilerde değișen varyans (heteroskedastic) sorunu çok fazla görülmemekle birlikte daha çok yatay kesit verilerinde rastlanmaktadır. Fakat yine de değișen varyans test edilmesi gerekir. $\mathrm{Bu}$ sorunu çözmek için araştırmada Reed ve Ye (2011) 'nin panel verilerde değișen varyans sorununu gidermek için kullandığ kovaryans yöntemi" olarak White (diagonal) kullanılacaktır.

\section{BULGULAR}

Çalışmamızda ön testler yapıldıktan sonra, dört model ile ilgili panel regresyon modeli uygulamaya sokulmuştur. Çoklu bağlantı, otokorelasyon ve heteroskedasite 
sorunlarından arındırılarak tahmin edilen bu modellerin sonuçları Tablo 5'de verilmiştir;

Tablo 5: Model 1ve Model 2'nin Regresyon Analizi Sonuçları

\begin{tabular}{|l|c|c|}
\hline Değişkenler & Model 1 & Model 2 \\
\hline C & 0,0662 & 0,0944 \\
\hline BS & $-0,0046$ & 0,0008 \\
\hline GBS & $0,0041^{*}$ & $0,0101^{*}$ \\
\hline KDO & 0,0451 & 0,1238 \\
\hline YKB & $-0,1882$ & $-0,4122$ \\
\hline Durbin-Watson & 2,1906 & 1,8521 \\
\hline R2 & 0,0300 & 0,0582 \\
\hline F-istatistiği & $2,2919^{* *}$ & $3,5823^{*}$ \\
\hline
\end{tabular}

${ }^{*} \mathrm{P}<0.01,{ }^{* *} \mathrm{P}<0.05,{ }^{* * *} \mathrm{P}<0.10$

Yukarıda açılanan Panel Veri Regresyon analizinin bulgularına bakıldığında, Model 1 ve Model 2'de sırasıyla aktif karlılık oranı ve öz sermaye karlılık oranı bağımlı değişken olarak kullanılmıştır. Sadece kurumsal yönetim ilkelerinin bağımsız değişken olarak alındığı bu modellerde F-istatistik olasılık değerine göre modeller genel olarak \% 5 ve $\% 1$ düzeyinde anlamlıdır. Bağımsız değişkenler bağımlı değişkenlerden aktif karlılık oranın \% 3'ünü ve öz sermaye karlılık oranın ise \% 5'ini açıklayabilmektedir. Her iki modelde de bağımsız değişkenlerden sadece CEO'nun görevde olduğu süre (GBS) \% 1 düzeyinde anlamlı çıkmış ve şirketin finansal performansını olumlu yönde etkilemektedir. Buna göre, KOBİlerde CEO'ların uzun süre görevde kalması firmanın kurumsallığına olumlu bir yönde etki yaparak, firma performansını yükseltmektedir.

Tablo 6: Model 3 ve Model 4'ün Regresyon Analizi Sonuçları

\begin{tabular}{|l|c|c|}
\hline Değişkenler & Model 3 & Model 4 \\
\hline C & $-0,6743$ & $-1,0424$ \\
\hline BS & $-0,0582$ & $-0,0724$ \\
\hline GBS & $0,0028^{* *}$ & $0,0073^{* *}$ \\
\hline KDO & 0,0435 & 0,1358 \\
\hline YKB & $-0,1396$ & $-0,2554$ \\
\hline TA & 0,0486 & 0,0735 \\
\hline NO & 0,0011 & 0,0018 \\
\hline DSO & 0,0889 & 0,1968 \\
\hline AT0 & $0,0017^{*}$ & $0,0020^{*}$ \\
\hline R $^{2}$ & 0,0790 & 0,0796 \\
\hline Durbin-Watson & 2,1053 & 1,7903 \\
\hline F-istatistiği & $2,7797^{*}$ & $2,7953^{*}$ \\
\hline
\end{tabular}

${ }^{*} \mathrm{P}<0.01,{ }^{* *} \mathrm{P}<0.05,{ }^{* * *} \mathrm{P}<0.10$
$\mathrm{Bu}$ çalıșmada daha sonra, modellere kontrol değişkenleri de ilave edilmiştir. Bu değişkenler firmaların finansal göstergeleri ile ilgilidir. $\mathrm{Bu}$ değişkenlerin eklenmesinin nedeni, güçlü olup olmadığını görmektir. Model 3'de aktif karlılık oranı bağımlı değişken olarak kullanılmıştır. Tablo 6 Model 3'in F-istatistik olasılık değerine göre model genel olarak \% 1 düzeyinde anlamlıdır. Ayrıca bağımsız değișkenler bağımlı değişkenin \% 7'sini açıklamaktadır. Model'de bağımsız değişkenlerden GBS ve ATO sırasıyla $\% 5$ ve \% 1 düzeyinde anlamlı çıkmıştır, diğer değişkenler ile bağımlı değişken arasında ise anlamlı istatistiksel bir değer çıkmamıştır. Modele giren kontrol değişkenleri CEO'nun görevde kalma süresi (GBS) değişkeninin anlamlılığını bir miktar düşürse bile, bu değişken hala \%5 düzeyinde anlamdır. Her iki değişken de aktif karlılık oranını pozitif etkilemektedir. Diğer değișkenler sabit kalmak koşuluyla, aktif karlılık oranını CEO'nun görevde kalma süresindeki 1 birimlik artış 0,002 birim, likidite oranındaki 1 birimlik artış ise 0,001 birim arttırmaktadır.

Öz sermaye karlılık oranının bağımlı değişsen olarak kullanıldığı Model 4'de de benzer sonuçlar çıkmıştır ve model genel olarak \% 1 düzeyinde anlamlıdır. GBS ve ATO değişkenleri sadece istatistiksel olarak anlamlı çıkmıştır. Her iki değișken sırasıyla \% 5 ve \% 1 düzeyinde anlamlıdır. Diğer değișkenler sabit kalmak şartıyla, CEO'nun görevde kalma süresindeki 1 birimlik artış, öz sermaye karlılık oranını 0,007 birim arttırırken, likidite oranındaki 1 birimlik artış ise öz sermaye karlılık oranını 0,002 birim arttırmaktadır. Yapılan analiz sonucunda ortaya çıkan modellerin sonuçları yorumlandığında Gelișen İşletme Pazarı'nda işlem gören KOBI'ler için CEO'nun görevde kalma süresi onların finansal performansları için önemli bir değişken olduğunu söyleyebiliriz.

Bu çalışmada Hambrick ve Fukutomi (1991), Miller ve Shamsie (2001), Simsek (2007) ile Luo Kanuri ve Andrews (2013) yaptıkları çalışmaları destekler nitelikte sonuçlar elde edilmiştir. $\mathrm{Bu}$ sonuç Bhagat, Bolton ve 
Subramanian (2010) Fidasnoski, Mateska ve Simeonovski (2013) ile Miller ve Yang'ın (2015) yaptıkları çalışmalarla paralellik göstermektedir.

\section{SONUÇ}

Günümüze gelindiğinde ekonomideki payı ve etkisi ilk sırada önem arz eden KOBİller, özellikle ülkede istihdamın gelişmesine önemli katkılar sağlamakta ve yoksulluğu azaltmadaki etkisiyle de milli gelir üzerinde kayda değer ölçüde olumlu etkileri vardır.

KOBİlerin finansmanında yatırımcıların doğru bilgiye ulaşmasında önemli sıkıntılar vardır. Aile şirketlerinin kapalı yapısı ve yönetim anlayıșı bankalar ve yatırımcılar açısından yanlış seçim ve ahlaki tehlike sorunlarının ortaya çıkmasına neden olmaktadır. $\mathrm{Bu}$ sorunların çözülebilmesi için, KOBİ'lerin kurumsallaşması gerekmektedir. IFC gibi birçok kurum bu konuda standartların gelişmesi için çalışmalar yürütmektedir. Ülkemizde de Borsa İstanbul uzun zamandır, KOBI borsalarının büyümesi ve kurumsal yönetim uygulamalarının yaygınlaştırılması için çaba sarf etmektedir.

$\mathrm{Bu}$ çalışmada, Borsa İstanbul'da ișlem gören KOBİlerin kurumsal yönetim ilkeleri ile finansal performansları kıyaslanarak bir sonuca varmak ve bu sonuçla da kurumsal yönetim ilkelerine eğilimi olan firmalara yol göstermek amaçlanmıştır. $\mathrm{Bu}$ açıdan bakıldığında ülkemiz bazında KOBI'ler için benzeri bir çalışma bulunmadı̆̆ından literatürdeki bu boşluğun doldurulması hedeflenmiştir. Ek olarak, günümüzün iki trendi olan kurumsal yönetim anlayışı ve KOBİ'lerin nasıl bir etkileşim içerisinde olduğu öğrenilmeye çalışılmıştır.
Yapılan analizler ıșığında KOBI'lerdeki kurumsal yönetimi hâkim kılıcı etmenlerin KOBİlerin finansal performansları üzerinde etkisi olduğuna dair genel bir kanıya varılamamıştır. Sadece CEO'nun görevde kalma süresinin, KOBİlerin finansal performansını belirli oranlarla ve kararlı bir şekilde olumlu yönde etkilediği sonucuna ulaşılmıştır. Tüm kurulan modellerde yüksek derece anlaml çlkmıştır. Bu sebeple CEO'nun uzun sure görevde kalması KOBİ'ler için önemli bir etken olduğu söylenebilir. CEO'nun uzun zaman görevde kalması Bhagat, Bolton ve Subramanian (2010), Fidasnoski, Mateska ve Simeonovski (2013) ile Miller ve Yang'ın (2015) gibi çalışmalarda ortaya konulduğu çalışmaları desteklemektedir. CEO' nun uzun süre görevde kalması firma yönetim istikrarını gösteren bir gösterge olarak kabul edildiğinden, ülkemizde firma performansı açısından yönetim istikrarın önemli olduğu görülmektedir.

KOBİlerin finansal performansı ile kurumsal yönetim ilkeleri arasındaki ilişkinin tam olarak açıklanamamasının en büyük sebebi, KOBİ'lerin henüz kurumsal yönetim ilkelerine tam olarak uyum göstermemeleridir. Bazı verilerin eksik olması da bu durumu tetiklemektedir. $\mathrm{Bu}$ sebeple bundan sonra yapılacak olan çalışmalarda bahsi geçen hususlar dikkate alındığında daha açıklayıcı sonuçlar elde edilebileceğini düşünüyoruz. Diğer taraftan CEO'nun görevde kalma süresi ile firma performansı ilişkisinin göreceli olarak daha büyük Borsa İstanbul şirketlerinde de incelenmesi ve önceki çalışmalarda olduğu gibi U şeklinde bir etki olup olmadığının araştırılması yararlı olacaktır.

\section{REFERANSLAR}

Abor, J., \& Adjasi , C. K. (2007). Corporate governance and the small and medium enterprises sector: theory and implications. Corporate Governance: The international journal of business in society, 111-122.
Abor, J., \& Biekpe , N. (2007). Corporate governance, ownership structure and performance of SMEs in Ghana: implications for financing opportunities. Corporate Governance: The international journal of business in society, 288-300. 
ACCA. (2015). Governance for all: the implementation challenge for SMEs. London: The Association of Chartered Certified Accountants .

Adams, B. R., \& Ferreira, D. (2009). Women in the boardroom and their impact on governance and performance. Journal of Financial Economics, 291-309.

Aebi, V., Sabato, G., \& Schmid, M. (2012). Risk management, corporate governance, and bank performance in the financial crisis. Journal of Banking \& Finance, 3213-3226.

Aghabaki, M. (2014). Kurumsal Yönetim İlkeleri İle Firma Değeri ve Hisse Senedi Getiri Oranı Arasındaki İlişki: İMKB'de Bir Uygulama Yayınlanmış Doktora Tezi. Erzurum: Atatürk Üniversitesi Sosyal Bilimler Enstitüsü.

Al-Najjar, B. (2014). Corporate governance, tourism growth and firm performance: Evidence from publicly listed tourism firms in five Middle Eastern countries. Tourism Management, 342-351.

Ammanna, M., Oesch, D., \& Schmid, M. M. (2011). Corporate governance and firm value: International evidence. Journal of Empirical Finance, 36-55.

Ararat, M., Black, B. S., \& Yurtoglu, B. (2017). The effect of corporate governance on firm value and profitability: Time-series evidence from Turkey. Emerging Markets Review, 113132.

Arslan, Ö., Karan, M. B., \& Ekşi, C. (2010). Board Structure and Corporate Performance. Managing Global Transitions: International Research Journal, 3-22.

Arthur, N. (2001). Board composition as the outcome of an internal bargaining process: empirical evidence. Journal of Corporate Finance, 307-340.

Baker, M., \& Gompers, P. A. (2003). The Determinants of Board Structure at the Initial Public Offering. Journal of Law and Economics, 569-598.
Baldo, M. D. (2012). Corporate social responsibility and corporate governance in Italian SMEs: the experience of some "spirited businesses". Journal of Management \& Governance, 1-36.

Balkan, B. (2014). Türk Bankacılık Sisteminde Kurumsal Yönetimin Krizlerin Çözümüne Etkileri Yayınlanmış Doktora Tezi. İstanbul: Marmara Üniversitesi Sosyal Bilimler Enstitüsü.

Beekes, W., Hong, A., \& Owen, S. A. (2010). An Alternative Measure of Corporate Governance Using Discrete Principal Component Analysis. Social Science Research Network (SSRN) Electronic Journal, 1-40.

Berger, A. N., \& Udell, G. F. (2002). Small Business Credit Availability and Relationship Lending: The Importance of Bank Organizational Structure. The Economic Journal, 32.

Bhagat, S., \& Black, B. S. (1998). The NonCorrelation between Board Independence and Long-Term Firm Performance. Journal of Corporation Law, 231-273.

Bhagat, S., \& Bolton, B. (2008). Corporate governance and firm performance. Journal of Corporate Finance, 257-273.

Bhagat, S., Bolton, B., \& Subramanian, A. (2010). CEO Education, CEO Turnover, and Firm Performance. Social Science Research Network (SSRN) Electronic Journal, 1-48.

Bhat, G., Hope, O.-K., \& Kang, T. (2006). Does Corporate Governance Transparency affect the Accuracy of Analyst Forecasts? Accounting and Finance, 715-732.

Boone, A. L., Field, L. C., Karpoff, J. M., \& Raheja, C. G. (2007). The determinants of corporate board size and composition: An empirical analysis. Journal of Financial Economics, 66101.

Borsa İstanbul. (2014). Gelişen İşletmeler Pazarı. İstanbul: Borsa İstanbul.

Borsa İstanbul. (2016, Kasım 14). Borsa İstanbul Anonim Şirketi. Mart 25, 2018 


\section{SAĞLAM M. - KARAN M.B.}

tarihinde Borsa İstanbul Anonim Şirketi: http://www.borsaistanbul.com/ data/ kilavuzlar/Gelisen-\%C4\%B0sletmelerPiyasasi.pdf adresinden alındı

Borsa İstanbul. (2018). Pay Piyasası. Mart 25, 2018 tarihinde Borsa İstanbul: http://www.borsaistanbul.com/urunler-vepiyasalar/piyasalar/pay-piyasasi adresinden alındı

Brunninge, O., Nordqvist, M., \& Wiklund, J. (2007). Corporate Governance and Strategic Change in SMEs: The Effects of Ownership, Board Composition and Top Management Teams. Small Business Economics, 295-308.

Ceyhan, O. (2014, Kasım 7). Dünya Borsalarının Şirket Sayısı, İşlem Hacmi ve Piyasa Değeri Karşılaştırması. Ocak 29, 2019 tarihinde Piyasa Rehberi:

http://piyasarehberi.org/piyasa/118-dunyaborsalari adresinden alındı

Cheng, S. (2008). Board size and the variability of corporate performance. Journal of Financial Economics, 157-176.

Coles, J. L., Daniel, N. D., \& L. N. (2008). Boards: Does one size fit all? Journal of Financial Economics, 329-356.

Dağlı, H., Ayaydın, H., \& Eyüboğlu, K. (2010). Kurumsal Yönetim Endeksi Performans Değerlendirmesi: Türkiye Örneği . Muhasebe ve Finansman Dergisi, 22.

Denetimnet. (2018, Şubat Çarşamba). Kurumsal Yönetim Endeksi İle İlgili Bilgiler. Mart Perşembe, 2018 tarihinde Denetimnet: www.denetimnet.net/PrintPage.aspx?pgID=69 98 adresinden alındı

Denis, D. J., \& Sarin, A. (1999). Ownership and board structures in publicly traded corporations. Journal of Financial Economics, 187-223.

Dey, A., Engel, E., \& Liu, X. (2011). CEO and board chair roles: To split or not to split? Journal of Corporate Finance, 1595-1618.

Drobetz, W., Schillhofer, A., \& Zimmermann, H. (2004). Corporate Governance and Firm
Performance: Evidence from Germany. European Financial Management, 267-293.

Erkens, H. D., Hung, M., \& Matos, P. (2012). Corporate governance in the 2007-2008 financial crisis: Evidence from financial institutions worldwide. Journal of Corporate Finance, 389-411.

Fidanoski, F., Mateska , V., \& Simeon, K. (2013). Corporate Governance and Bank Performance: Evidence from Macedonia. Published in: Proceedings [CD- ROM] of 16th International Students' Conference. Izmir: Faculty of Economics and Administrative Sciences, Ege University.

Fizel, J. L., \& Louie, K. K. (1990). CEO Retention, Firm Performance and Corporate Governance. Managerial and Decision Economics, 167-176.

Granger, C., \& Newbold, P. (1974). Spurius Regression in Econometrcis. Journal of Econometrics, 111-120.

Grinstein, Y., \& Grinstein, Y. (2008). Separating the CEO from the Chairman Position: Determinants and Changes after the New Corporate Governance Regulation. SSRN Electronic Journal, 1-47.

Guest, P. M. (2009). The Impact of Board Size on Firm Performance: Evidence from the UK. The European Journal of Finance, 385-404.

Gujarati, D. N. (2004). Why Panel Data. D. N. Gujarati içinde, Basic Econometrics, Fourth Edition (s. 637-638). New York: The McGrawHill Companies.

Hambrick, D. C., \& Fukutomi, G. D. (1991). The Seasons of a CEO's Tenure. The Academy of Management Review, 719-742.

Haniffa, R., \& Hudaib, M. (2006). Corporate Governance Structure and Performance of Malaysian Listed Companies. Journal of Business Finance \& Accounting, 1034-1062.

Hillier, D., \& McColgan, P. (2006). An Analysis of Changes in Board Structure during Corporate Governance Reforms. European Financial Management, 575-607. 
Kanagaretnam, K., Lobo, G. J., \& Whalen, D. J. (2007). Does good corporate governance reduce information asymmetry around quarterly earnings announcements? Journal of Accounting and Public Policy, 497-522.

Kerr, J., \& A.Bettis, R. (1987). Boards of Directors, Top Management Compensation, and Shareholder Returns. Academy of Management Journal, 645-664.

Kutlar, A. (2007). Ardışık Bağımlılık. A. Kutlar içinde, Ekonometriye Giriş (s. 181). Ankara: Nobel.

Lasfer, M. A. (2006). The Interrelationship Between Managerial Ownership and Board Structure. Journal of Business Finance \& Accounting, 1006-1033.

Linck, J. S., Netter, J. M., \& Yang, T. (2008). The determinants of board structure. Journal of Financial Economics, 308-328.

Luo, X., Kanuri, V. K., \& Andrews, M. (2013). How Does CEO Tenure Matter? The Mediating Role of Firm-Employee and Firm-Customer Relationship. Strategic Management Journal, 492-511.

Maddala, G. S., \& Wu, S. (1999). A Comparative Study of Unit Root Tests With Panel Data and A New Simple Test. Oxford Bulletin of Economics and Statistics, Special Issue, 631-652.

Mak, Y., \& Li, Y. (2001). Determinants of corporate ownership and board structure: evidence from Singapore. Journal of Corporate Finance, 235-256.

Mashayekhi, B., \& Bazaz, M. S. (2008). Corporate Governance and Firm Performance in Iran. Journal of Contemporary Accounting \& Economics, 156-172.

Miller, D., \& Shamsie, J. (2001). Learning across the Life Cycle: Experimentation and Performance among the HollywoodStudio Heads. Strategic Management Journal, 725-745.

Miller, S., \& Yang, T. (2015). Board Leadership Structure of Publicly-Traded Insurance Companies. Journal of Insurance Issues, 184232.
Molz, R. (1995). The Theory of Pluralism in Corporate Governance: A Conceptual Framework and Empirical Test. Journal of Business Ethics, 789-804.

Oral, C. (2017, Haziran 23). Yabancilar en çok hangi hisseleri alıyor? Ocak 10, 2019 tarihinde Ekonomist:

https://www.ekonomist.com.tr/borsa/yabanc ilar-en-cok-hangi-hisseleri-aliyor.html adresinden alındı

Pathan, S., \& Skully, M. (2010). Endogenously structured boards of directors in banks. Journal of Banking \& Finance, 1590-1606.

Rechner, P. L., \& Dalton, D. R. (1991). CEO Duality and Organizational Performance: A Longitudinal Analysis. Strategic Management Journal, 155-160.

Reed, W. R., \& Ye, H. (2011). Which panel data estimator should I use? Applied Economics, 985-1000.

Sakarya, Ş. (2011). İMKB Kurumsal Yönetim Endeksi Kapsamındaki Şirketlerin Kurumsal Yönetim Derecelendirme Notu ve Hisse Senedi Getirileri Arasındaki İlişkinin Olay Çalışması ( Event Study) Yöntemi ile Analizi. Zonguldak Kara Elmas Ünivversitesi Sosyal Bilimler Dergisi, 147-162.

Simsek, Z. (2007). CEO Tenure and Organizational Performance: An Intervening Model. Strategic Management Journal, 653662.

SPK. (2005). Kurumsal Yönetim İlkeleri. Ankara: SPK.

Stock, J. H., \& Watson, M. W. (2011). Sabit Etkiler Regresyonu. B. Saraçoğlu içinde, Ekonometriye Giriş (s. 358). Ankara: Efil Yayınevi.

Stock, J. H., \& Watson, M. W. (2011). Panel Veriler. B. Saraçoğlu içinde, Ekonometriye Giriş (s. 13). Ankara: Efil.

T.C. Bilim Sanayi ve Teknoloji Bakanlığı. (2012, Kasım 1). KOBİ'ler ve Girişimcilik. Kalkınmada Anahtar Verimlilik, s. 4. 
Tatoğlu, F. Y. (2012). Panel Veri. F. Y. Tatoğlu içinde, Panel Veri Ekonometrisi Stata Uygulamalı (s. 3). İstanbul: Beta.

TKYD. (2011). Ekonmi Gazeteciliği İçin Kurumsal Yönetim El Kitabı. İstanbul: Türkiye Kurumsal Yönetim Derneği Yayınları.

TÜSİAD. (2002). Kurumsal Yönetim En İyi Uygulama Kodu: Yönetim Kurulunun Yapısı ve İşleyişi. İstanbul: TÜSİAD.

Vintila, G., \& Paunescu, R. A. (2016). Empirical Analysis of the Connection between Financial Performance and Corporate Governance within Technology Companies Listed on NASDAQ Stock Exchange. Journal of Financial Studies \& Research, 1-20.
Yasan, A. (2016). KOBİ'lerde Yönetim Kuru Yapısının ve Yönetim Kurulu Kararlarının Şirket Performansına Etkisi Yayınlanmış Doktora Tezi. İzmit: Gebze Teknik Üniversitesi Sosyal Bilimler Enstitüsü.

Yermack, D. (1996). Higher market valuation of companies with a small board of directors. Journal of Financial Economics 40, 185-211.

Yılmaz, C. (2016). The Effect of Board Structure and Foreign Ownership on Firm Performance: Turkey Case Published Ph.D Thesis. İstanbul: Okan Üniversitesi Sosyal Bilimler Enstitüsü.

Yılmaz, F. Ö. (2011). Bankalarda Kurumsa Yönetim - Entelektüel Sermaye İlişkisi. Selçuk Üniversitesi Sosyal Bilimler Meslek Yüksekokulu Dergisi, 1-12. 